\title{
True mitral annulus diameter is underestimated by two- dimensional echocardiography as evidenced by real-time three-dimensional echocardiography and magnetic resonance imaging
}

\author{
Ashraf M. Anwar · Osama I. I. Soliman · Folkert J. ten Cate • \\ Attila Nemes · Jackie S. McGhie · Boudewijn J. Krenning • \\ Robert-Jan van Geuns $\cdot$ Tjebbe W. Galema $\cdot$ Marcel L. Geleijnse
}

Received: 1 August 2006/ Accepted: 9 October 2006/Published online: 13 December 2006

(C) Springer Science+Business Media B.V. 2006

\begin{abstract}
Background Mitral annulus assessment is of great importance for the diagnosis and treatment of mitral valve disease. The present study sought to assess the value of real-time three-dimensional echocardiography for the assessment of true mitral annulus diameter (MAD).

Methods One hundred and fifty patients (mean age $38 \pm 18$ years) with adequate two-dimensional (2D) echocardiographic image quality underwent assessment of $\mathrm{MAD}_{2 \mathrm{D}}$ and $\mathrm{MAD}_{3 \mathrm{D}}$ (with real-time three-dimensional echocardiography). In a subgroup of 30 patients true MAD was validated with magnetic resonance imaging (MRI).

Results There was a good interobserver agreement for $\mathrm{MAD}_{2 \mathrm{D}}$ (mean difference $=-0.25 \pm 2.90 \mathrm{~mm}$, agreement: $-3.16,2.66)$ and $\mathrm{MAD}_{3 \mathrm{D}}$ (mean difference $=0.29 \pm 2.03, \quad$ agreement $=-1.74, \quad 2.32$ ) . Measurements of $\mathrm{MAD}_{2 \mathrm{D}}$ and $\mathrm{MAD}_{3 \mathrm{D}}$ were well
\end{abstract}

A. M. Anwar · O. I. I. Soliman · F. J. ten Cate $(\bowtie)$.

A. Nemes - J. S. McGhie - B. J. Krenning .

R.-J. van Geuns · T. W. Galema · M. L. Geleijnse

Thoraxcenter, Room Ba 302, Erasmus MC,

Dr. Molewaterplein 40, 3015 GD Rotterdam,

The Netherlands

e-mail: f.j.tencate@erasmusmc.nl

A. M. Anwar · O. I. I. Soliman

Cardiology Department, Al-Husein University

Hospital, Al-Azhar University, Cairo, Eygpt correlated $(R=0.81, \quad P<0.0001)$. However, $\mathrm{MAD}_{3 \mathrm{D}}$ was significantly larger than $\mathrm{MAD}_{2 \mathrm{D}}$ $(3.7 \pm 0.9$ vs. $3.3 \pm 0.8 \mathrm{~cm}, P<0.0001)$. In the subgroup of 30 patients with MRI validation, $\mathrm{MAD}_{3 \mathrm{D}}$ and $\mathrm{MAD}_{\mathrm{MRI}}$ were significantly larger than $\mathrm{MAD}_{2 \mathrm{D}}(3.3 \pm 0.5$ and $3.4 \pm 0.5 \mathrm{~cm}$ vs. $2.9 \pm 0.4 \mathrm{~cm}$, both $P<0.001)$. There was no significant difference between MAD $_{\text {MRI }}$ and $\mathrm{MAD}_{3 \mathrm{D}}$.

Conclusion $\mathrm{MAD}_{3 \mathrm{D}}$ can be reliably measured and is superior to $\mathrm{MAD}_{2 \mathrm{D}}$ in the assessment of true mitral annular size.

Keywords Mitral annulus - Real-time three-dimensional echocardiography $\cdot$ Magnetic resonance imaging

\section{Introduction}

The mitral annulus (MA) is a vital component of the mitral valve apparatus and plays a crucial role in left ventricular and left atrial function [1]. The MA marking the hinge line of the mitral valve leaflets is more D-shaped than circular as portrayed by prosthetic rings. The straight border accommodates the aortic valve allowing this valve to be wedged between the interventricular septum and the mitral valve. Although the term annulus implies a solid ring-like fibrous cord to which the leaflets are attached, this is not the case 
[2]. Therefore, some authors used the term "aortoventricular membrane" instead of MA, to emphasize that there is an extension of this fibrous cord into the subvalvular region [3]. MA assessment is of great importance for the diagnosis and treatment of mitral valve disease. MA dilatation is one of the main mechanisms for development of mitral regurgitation and selection of the optimal individual therapy for mitral regurgitation depends on MA size and function $[4,5]$. This has been studied in both animals and humans using echocardiography, sonomicrometry and magnetic resonance imaging (MRI) [6-11]. The present study aimed to assess true MA diameter (MAD) by comparing two-dimensional echocardiography (2DE), real-time three-dimensional echocardiography (RT3DE), and MRI as gold standard.

\section{Patients and methods}

The study included 150 patients (Table 1) randomly selected from our 3D database that included relatively young patients in sinus rhythm (mean age $38 \pm 18$ years) with adequate $2 \mathrm{DE}$ image quality. Age, gender, weight and height of all patients were recorded and body surface area was calculated by the standard formula (weight $^{0.425}$ in kilograms $\times$ height $^{0.725}$ in centimeters $\times 0.007184)$. In all patients, $2 \mathrm{DE}$ and RT3DE were performed.

2DE was undertaken with the patient lying in the left lateral decubitus position using both apical and parasternal views. 2DE studies were performed using a $3.5 \mathrm{MHz}$ probe and a commercially available ultrasound system (Philips Sonos 7500, Best, The Netherlands). The following measures were obtained: (1) MA diameter

Table 1 Clinical categorization of patients $(n=150)$

\begin{tabular}{ll}
\hline Category & $N(\%)$ \\
\hline Normal & $52(34 \%)$ \\
Congenital heart disease & $48(32 \%)$ \\
Ischemic heart disease & $20(14 \%)$ \\
Valvular disease & $20(14 \%)$ \\
Cardiomyopathy & $10(6 \%)$ \\
\hline
\end{tabular}

$\left(\mathrm{MAD}_{2 \mathrm{D}}\right)$ obtained from an apical 4-chamber view at end-diastole (just before mitral valve closure), and (2) MAD index (MADI $2 \mathrm{D})$ calculated as $\mathrm{MAD}_{2 \mathrm{D}} /$ body surface area.

RT3DE was done with the same ultrasound system attached to a $\mathrm{X} 4$ matrix array transducer capable of providing real-time B-mode images. A full volume 3D data set was collected within approximately 5-10 s of breath holding in full volume mode from an apical window. The 3D data set was stored digitally and transferred for off-line analysis with TomTec software (Unterschleissheim, Munich, Germany). Two blinded observers (AMA, OIIS) subsequently evaluated all data. Data analysis of 3D images was based on a 2D approach relying on images obtained initially from the apical view. The MA was sliced between two narrow lines to exclude other tissue on the 2D image leading to clarification of the $\mathrm{MA}$ in the 3D image. The 3D image of the MA was viewed and traced from the ventricular aspect. Manual tracing of the inner border of the MA was done and once this was completed the surface area was automatically delineated and could be visualized from different points of views. The following RT3DE data were obtained: (1) end-diastolic $\mathrm{MAD}_{3 \mathrm{D}}$ defined as the perpendicular line drawn from the top of the MA curvature to the middle of the straight MA border (see Fig. 1), (2) end-diastolic MA area $\left(\mathrm{MAA}_{3 \mathrm{D}}\right)$, (3) $\mathrm{MAD}_{3 \mathrm{D}}$ index $\left(\mathrm{MADI}_{3 \mathrm{D}}\right)$ calculated as $\mathrm{MAD}_{3 \mathrm{D}} /$ body surface area, and (4) $\mathrm{MAA}_{3 \mathrm{D}}$ index $\left(\mathrm{MAAI}_{3 \mathrm{D}}\right)$ calculated as $\mathrm{MAA}_{3 \mathrm{D}} /$ body surface area.

Normal values for $\mathrm{MAD}_{2 \mathrm{D}}, \mathrm{MAD}_{3 \mathrm{D}}$, $\mathrm{MADI}_{3 \mathrm{D}}, \mathrm{MAA}_{3 \mathrm{D}}$, and $\mathrm{MAAI}_{3 \mathrm{D}}$ were established in 25 patients without apparent left-sided heart disease (defined as normal left atrial and ventricular dimension and function with normal mitral valve function).

In a non-selected group of 30 patients, MRI was performed with a $1.5 \mathrm{~T}$ MRI (General Electric, Signa $1.5 \mathrm{~T}$ MRI, Milwaukee WI) equipped with a for-element cardio coil. An ECG-triggered, steady state, free-precession sequence (FIESTA; repetition time and time of echo of 3.5 and $1.4 \mathrm{~ms}$, respectively, 12 shots, temporal resolution of $42 \mathrm{~ms}$, flip angle of $45^{\circ}$ ) was used for quantitative analysis. Ten cine short 
Fig. 1 Real-time threedimensional echocardiographic images from the ventricular aspect of normal (A, top left) and dilated (B, top right) mitral annulus morphology. The Dshaped morphology can be clearly appreciated, as confirmed by the magnetic resonance images ( $\mathbf{C}, \mathbf{D}$ bottom) the straight border of $\mathbf{D}$ is anterior and the curvature is posterior. In all figures the white line indicates mitral annular diameter
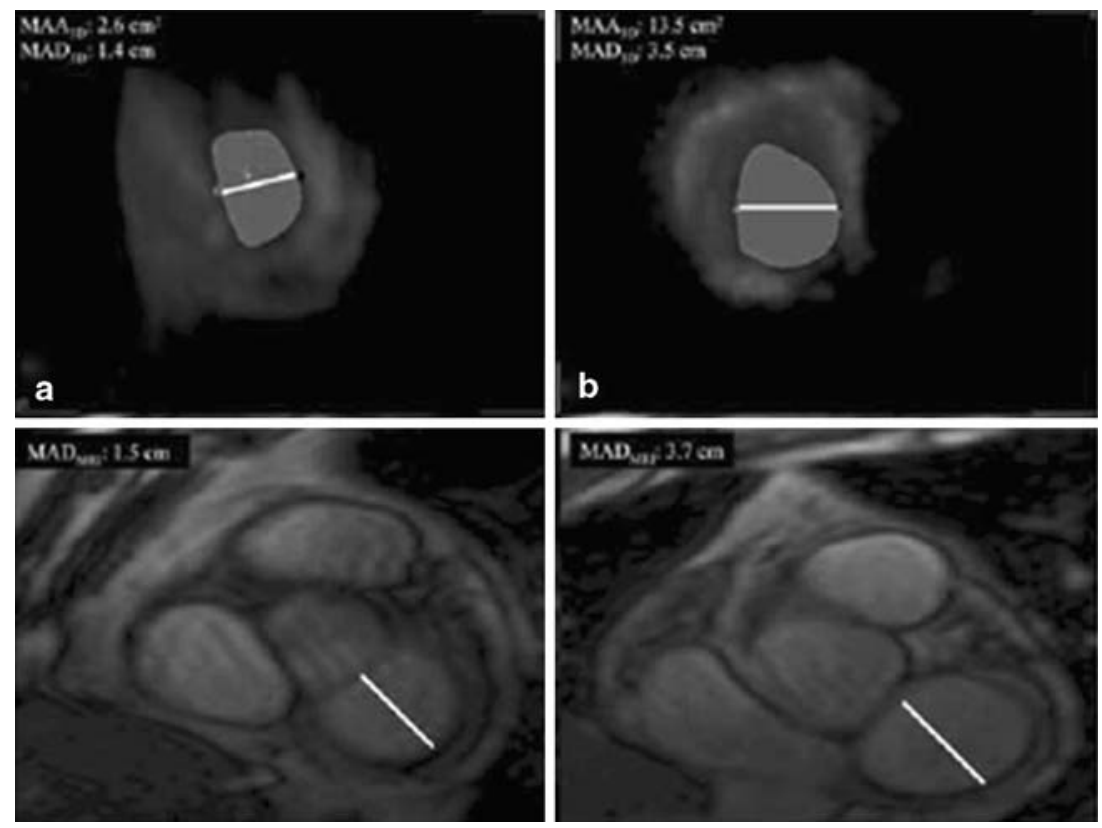

axis slices were acquired (slice thickness $8 \mathrm{~mm}$, gap $2 \mathrm{~mm}$ ) covering the heart from the base to the apex. Additional imaging parameters were a field of view of $320-380 \mathrm{~mm}$ and a matrix of $160 \times 128$. Quantitative measurements were performed using standardized Dicom viewing software on the basal slice demonstrating the mitral valve annulus in end-diastole. MAD MRI $_{\text {was }}$ defined as described before in the RT3DE section (see Fig. 1).

\subsection{Statistical analysis}

All data obtained by 2DE, RT3DE, and MRI were presented as mean $\pm \mathrm{SD}$. Data analyses were performed using statistical software (SPSS, version 12.1, SPSS Inc, Chicago). A paired sample $t$-test was performed to compare between means of variables of techniques. The difference in values was considered statistically significant with the level of $P<0.05$. Pearson's coefficient was used for correlation between variables. Interobserver and intraobserver agreements were assessed for $\mathrm{MAD}_{2 \mathrm{D}}$ and $M A D_{3 \mathrm{D}}$ in the first 100 patients and expressed according to the Bland and Altman method [12].

\section{Results}

Acquisition and post-processing of RT3DE data were performed successfully in all patients within a reasonable time (approximately $1 \mathrm{~min}$ for acquisition and $5 \mathrm{~min}$ for data analysis). The MA was clearly delineated in all patients and, as seen in Fig. 1, its shape was not circular but D-shaped, both in normal sized and in dilated MA. As seen in Fig. 2, in the total group of 150 patients, measurements of $\mathrm{MAD}_{2 \mathrm{D}}$ and $\mathrm{MAD}_{3 \mathrm{D}}$ were well correlated $(R=0.81 ; P<0.0001)$. However, $\mathrm{MAD}_{3 \mathrm{D}}$ was significantly larger than $\mathrm{MAD}_{2 \mathrm{D}}(3.7 \pm 0.9$ vs. $3.3 \pm 0.8 \mathrm{~cm}, P<0.0001)$.

\subsection{Surgical validation}

In three patients referred for mitral valve repair, $\mathrm{MAD}_{3 \mathrm{D}}$ matched with $\mathrm{MAD}$ measured by the surgeon (who was blinded to $\mathrm{MAD}_{3 \mathrm{D}}$ measurement) while $\mathrm{MAD}_{2 \mathrm{D}}$ assessed by preoperative transthoracic $2 \mathrm{DE}$ and intraoperative transesophageal echo was smaller than the surgical measurement. 
Fig. 2 Correlation between two-dimensional and three-dimensional echocardiographic mitral annulus diameter measurements in 150 patients (A), and in subgroup of 30 patients (B-D) that underwent magnetic resonance imaging
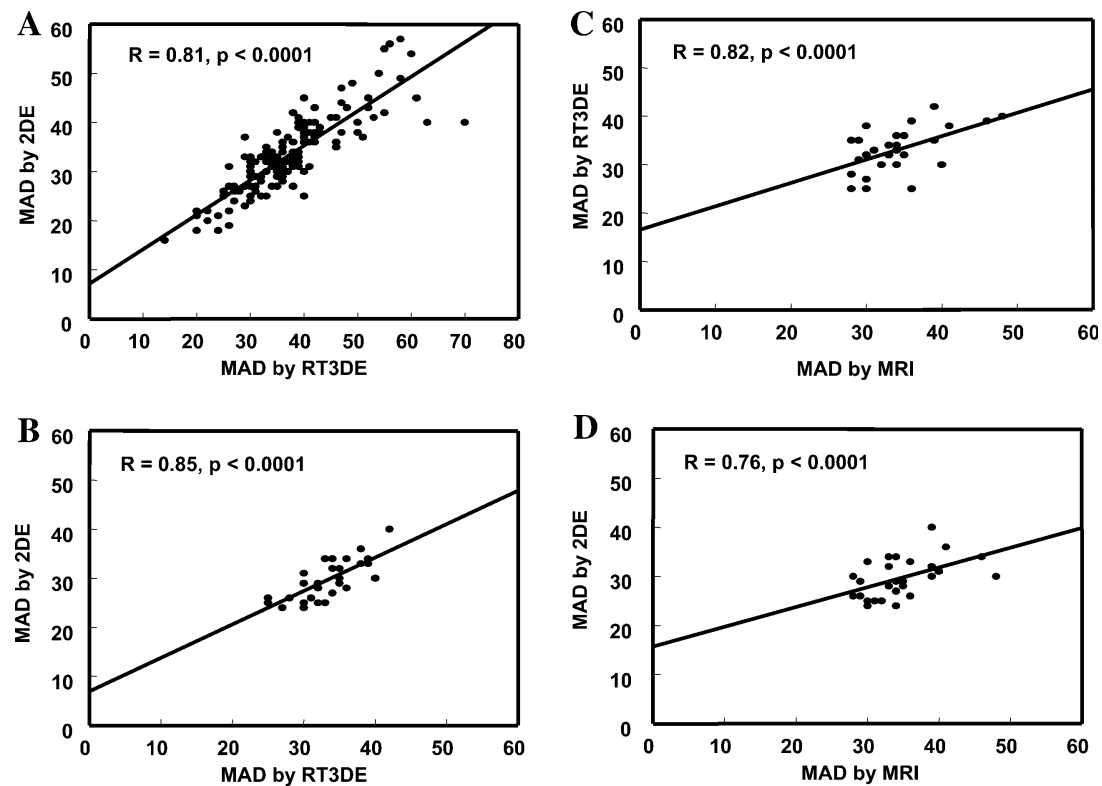

\subsection{MRI validation}

In the subgroup of 30 patients who underwent 2DE, RT3DE, and MRI, the D-shaped MA was confirmed by the MRI images (Fig. 1D). As seen in Fig. 3, $\mathrm{MAD}_{2 \mathrm{D}}, \mathrm{MAD}_{3 \mathrm{D}}$, and $M A \mathrm{D}_{\mathrm{MRI}}$ were well correlated. $\mathrm{MAD}_{3 \mathrm{D}}$ and $\mathrm{MAD}_{\mathrm{MRI}}$ were significantly larger than $\mathrm{MAD}_{2 \mathrm{D}} \quad(3.3 \pm 0.5$ and $3.4 \pm 0.5 \mathrm{~cm}$ vs. $2.9 \pm 0.4 \mathrm{~cm}$, both $P<0.001)$.
There was no significant difference between $\mathrm{MAD}_{\mathrm{MRI}}$ and $\mathrm{MAD}_{3 \mathrm{D}}$. Also, there was no significant difference between $\mathrm{MAA}_{3 \mathrm{D}}$ and MAA $\mathrm{MRI}$ (Table 2).

\subsection{Normal RT3DE values}

Normal values assessed in patients without apparent left-sided heart disease were $2.5 \pm 0.5 \mathrm{~cm}$ for
Fig. 3 Correlations and interobserver agreements of mitral annulus diameter as measured by two-dimensional and three-dimensional echocardiography
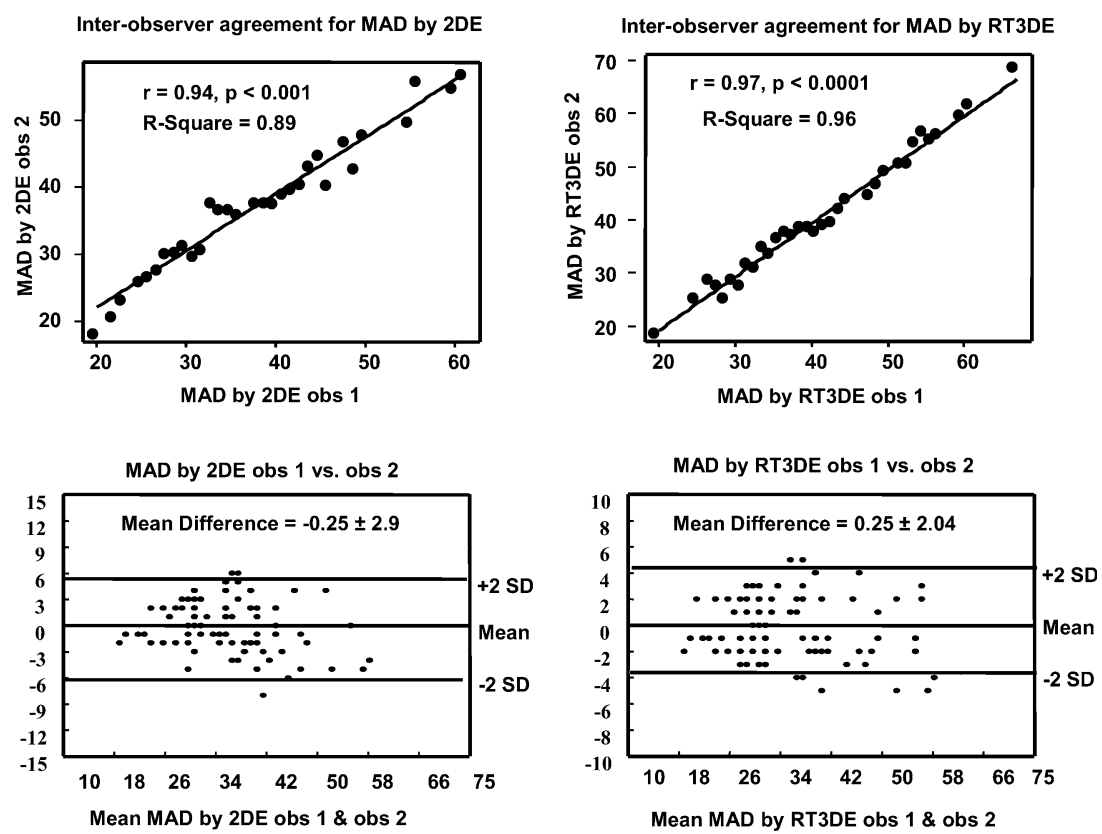
Table 2 Comparison between RT3DE and MRI measurements

\begin{tabular}{lll}
\hline & RT3DE & MRI \\
\hline Diastolic MAA $\left(\mathrm{cm}^{2}\right)$ & $8.7 \pm 2.9$ & $9.0 \pm 2.3$ \\
Diastolic MAAI $\left(\mathrm{cm}^{2} / \mathrm{m}^{2}\right)$ & $4.7 \pm 1.8$ & $4.8 \pm 2.0$ \\
Diastolic MAD $(\mathrm{cm})$ & $3.3 \pm 0.5$ & $3.4 \pm 0.5$ \\
Diastolic MADI $\left(\mathrm{cm} / \mathrm{m}^{2}\right)$ & $1.8 \pm 0.5$ & $1.8 \pm 0.7$ \\
\hline
\end{tabular}

Abbreviation: MAA - mitral annulus area; MAAI-mitral annulus area index; MAD—mitral annulus diameter; MADI-mitral annulus diameter index

$\mathrm{MAD}_{2 \mathrm{D}}, 2.8 \pm 0.6 \mathrm{~cm}$ for $\mathrm{MAD}_{3 \mathrm{D}}, 1.5 \pm 0.3 \mathrm{~cm} /$ $\mathrm{m}^{2}$ for $\mathrm{MADI}_{3 \mathrm{D}}, 8.1 \pm 2.4 \mathrm{~cm}^{2}$ for $\mathrm{MAA}_{3 \mathrm{D}}$, and $4.3 \pm 0.8 \mathrm{~cm}^{2} / \mathrm{m}^{2}$ for $\mathrm{MAAI}_{3 \mathrm{D}}$.

\subsection{Interobserver and intraobserver} agreements

As seen in Fig. 3, there was a good interobserver agreement for $\mathrm{MAD}_{2 \mathrm{D}}$ (mean difference $=$ $-0.25 \pm 2.90 \mathrm{~mm}$, agreement:-3.16, 2.66) and $\mathrm{MAD}_{3 \mathrm{D}} \quad($ mean difference $=0.29 \pm 2.03 \mathrm{~mm}$, agreement $=-1.74,2.32)$. Likewise, there was a good intraobserver agreement for $\mathrm{MAD}_{2 \mathrm{D}}$ (mean difference $=-0.23 \pm 2.28 \mathrm{~mm}$, agreement $=-2.51$, 2.05) and $\mathrm{MAD}_{3 \mathrm{D}}$ (mean difference $=-0.10 \pm$ $3.00 \mathrm{~mm}$, agreement $=-3.10,2.92)$.

\section{Discussion}

Assessment of MA size is an important issue in patients with mitral valve disease. An increase in MAD results in reduced mitral valve leaflet coaptation and thus an increase in the incidence and severity of mitral regurgitation [13, 14]. Reduction in MAD is an essential element in mitral valve repair and prevention of regurgitation not only in organic mitral valve disease, but also in ischemic mitral regurgitation $[15,16]$. Accurate assessment of MAD is crucial for the selection of a proper sized prosthetic ring, percutaneous annuloplasty device or stented valve implantation [17-19]. The current study showed that in patients with adequate 2DE image quality, the MA could be well visualized from the ventricular (and atrial) aspect with RT3DE. $\mathrm{MAD}_{3 \mathrm{D}}$ could be reliably measured with

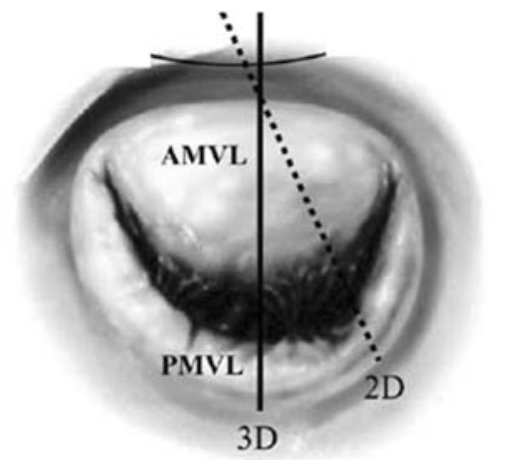

Fig. 4 RT3DE and 2DE (dashed line) measurement of mitral annulus diameter. AMVL_anterior mitral valve leaflet; PMVL_-posterior mitral valve leaflet

excellent inter- and intraobserver agreements. The main finding in our study was a significant underestimation of true MAD by $\mathrm{MAD}_{2 \mathrm{D}}$ as evidenced by $\mathrm{MAD}_{3 \mathrm{D}}$ and $\mathrm{MAD}_{\mathrm{MRI}}$ measurements. Because of the relatively fixed MA trigone, changes in MAD size (regardless whether these are due to cyclic changes in the heart cycle or to a pathological process such as left ventricular dilatation) [7] occur mainly along the axis represented by the perpendicular line drawn from the top of the MA curvature to the middle of the straight MA. As seen in Fig. 4, it is this MAD that we measure with RT3DE, whereas with 2DE an underestimated MAD is measured. $\mathrm{MAD}_{3 \mathrm{D}}$ and MAD $_{\text {MRI }}$ were well correlated with no significant difference in between these measurements. The underestimation of true MAD may explain the frequently encountered discrepancy between preoperative $\mathrm{MAD}_{2 \mathrm{D}}$ assessment and implanted ring-prosthesis size [20]. Because of the limited information available in the literature we assessed normal MAD and MAA in patients without apparent left-sided heart disease. With variable methods available for MAA measurements, the definition of normal MAA is quite variable, probably caused by the complex geometry of the MA. MAA $_{2 \mathrm{D}}$ measurements in other studies $[9,21]$ ranged from $6.9 \pm 0.8$ to $12.2 \pm 3.8 \mathrm{~cm}^{2}$. In two recent, very small studies (with 10 and 7 subjects, respectively) [7, 22], normal transesophageal assessed $\mathrm{MAA}_{3 \mathrm{D}}$ values were $11.8 \pm 2.5 \mathrm{~cm}^{2}$ and normal MAA $\mathrm{ARI}_{\mathrm{M}}$ values were $9.5 \pm 1.4 \mathrm{~cm}^{2}$. MAA values in fresh human 
autopsy specimens [23] ranged from 6.4 to $8.2 \mathrm{~cm}^{2}$. In our study, $\mathrm{MAA}_{3 \mathrm{D}}$ in normal subjects was $8.1 \pm 2.4 \mathrm{~cm}^{2}$ or $\left(4.3 \pm 0.8 \mathrm{~cm}^{2} / \mathrm{m}^{2}\right)$ when corrected for body surface area.

\subsection{Study limitations}

The study excluded patients with bad image quality and/or in non-sinus rhythm because RT3DE is totally dependent on 2D images and the analysis of full volume mode will not be achieved with variable heart rate. Another limitation was that the surgical measurements of MAD were obtained only in three cases.

\section{Conclusion}

$\mathrm{MAD}_{3 \mathrm{D}}$ can be reliably measured in patients with adequate image quality and is superior to $\mathrm{MAD}_{2 \mathrm{D}}$ in the assessment of true MA size. Normal values for $\mathrm{MAD}_{3 \mathrm{D}}$ are $2.8 \pm 0.6 \mathrm{~cm}$ (or indexed for body surface area $1.5 \pm 0.3 \mathrm{~cm} / \mathrm{m}^{2}$ ) and for $\mathrm{MAA}_{3 \mathrm{D}} 8.1 \pm 2.4 \mathrm{~cm}^{2}$ (or indexed for body surface area $4.3 \pm 0.8 \mathrm{~cm}^{2} / \mathrm{m}^{2}$ )

\section{References}

1. Timek TA, Dagum P, Lai DT, Liang D, Daughters GT, Ingels NB Jr, Miller DC (2001) Pathogenesis of mitral regurgitation in tachycardia-induced cardiomyopathy. Circulation 104:I47-I53

2. Ho SY (2002) Anatomy of the mitral valve. Heart 88 Suppl 4:iv5-iv10

3. Boudoulas H, Wooley CF (2001) Floppy mitral valve, mitral valve prolapse, and mitral valvular regurgitation. Curr Treat Options Cardiovasc Med 3:15-24

4. De Simone R, Wolf I, Mottl-Link S, Hoda R, Mikhail B, Sack FU, Meinzer HP, Hagl S (2006) A clinical study of annular geometry and dynamics in patients with ischemic mitral regurgitation: new insights into asymmetrical ring annuloplasty. Eur J Cardiothorac Surg 29:355-361

5. Mihalatos DG, Mathew ST, Gopal AS, Joseph S, Grimson R, Reichek N (2006) Relationship of mitral annular remodeling to severity of chronic mitral regurgitation. J Am Soc Echocardiogr 19:76-82

6. Gorman JH 3rd, Gupta KB, Streicher JT, Gorman RC, Jackson BM, Ratcliffe MB, Bogen DK, Edmunds LH Jr (1996) Dynamic three-dimensional imaging of the mitral valve and left ventricle by rapid sonomicrometry array localization. J Thorac Cardiovasc Surg 112:712726

7. Komoda T, Hetzer R, Uyama C, Siniawski H, Maeta H, Rosendahl UP, Ozaki K (1994) Mitral annular function assessed by 3D imaging for mitral valve surgery. J Heart Valve Dis 3:483-490

8. Cosgrove DM 3rd, Arcidi JM, Rodriguez L, Stewart WJ, Powell K, Thomas JD (1995) Initial experience with the Cosgrove-Edwards Annuloplasty System. Ann Thorac Surg 60:499-503, discussion 503-504

9. Pai RG, Tanimoto M, Jintapakorn W, Azevedo J, Pandian NG, Shah PM (1995) Volume-rendered threedimensional dynamic anatomy of the mitral annulus using a transesophageal echocardiographic technique. J Heart Valve Dis 4:623-627

10. Yamaura Y, Yoshikawa J, Yoshida K, Hozumi T, Akasaka T, Okada Y (1995) Three-dimensional analysis of configuration and dynamics in patients with an annuloplasty ring by multiplane transesophageal echocardiography: comparison between flexible and rigid annuloplasty rings. J Heart Valve Dis 4:618-622

11. Kaji S, Nasu M, Yamamuro A, Tanabe K, Nagai K, Tani T, Tamita K, Shiratori K, Kinoshita M, Senda M, Okada Y, Morioka S (2005) Annular geometry in patients with chronic ischemic mitral regurgitation: three-dimensional magnetic resonance imaging study. Circulation 112:I409-I414

12. Bland JM, Altman DG (1986) Statistical methods for assessing agreement between two methods of clinical measurement. Lancet 1:307-310

13. Enriquez-Sarano M, Basmadjian AJ, Rossi A, Bailey KR, Seward JB, Tajik AJ (1999) Progression of mitral regurgitation: a prospective Doppler echocardiographic study. J Am Coll Cardiol 34:1137-1144

14. Srichai MB, Grimm RA, Stillman AE, Gillinov AM, Rodriguez LL, Lieber ML, Lara A, Weaver JA, McCarthy PM, White RD (2005) Ischemic mitral regurgitation: impact of the left ventricle and mitral valve in patients with left ventricular systolic dysfunction. Ann Thorac Surg 80:170-178

15. Czer LS, Maurer G, Bolger AF, DeRobertis M, Chaux A, Matloff JM (1996) Revascularization alone or combined with suture annuloplasty for ischemic mitral regurgitation. Evaluation by color Doppler echocardiography. Tex Heart Inst J 23:270-278

16. Baba H, Okawa Y, Koike S, Hashimoto M, Matsumoto K (1997) [The causes and management of ischemic mitral regurgitation] Nippon Kyobu Geka Gakkai Zasshi 45:543-549

17. Maniu CV, Patel JB, Reuter DG, Meyer DM, Edwards WD, Rihal CS, Redfield MM (2004) Acute and chronic reduction of functional mitral regurgitation in experimental heart failure by percutaneous mitral annuloplasty. J Am Coll Cardiol 44:1652-1661

18. Ma L, Tozzi P, Huber CH, Taub S, Gerelle G, von Segesser LK (2005) Double-crowned valved stents for off-pump mitral valve replacement. Eur J Cardiothorac Surg 28:194-8, discussion 198-199

19. Webb JG, Harnek J, Munt BI, Kimblad PO, Chandavimol M, Thompson CR, Mayo JR, Solem JO 
(2006) Percutaneous transvenous mitral annuloplasty: initial human experience with device implantation in the coronary sinus. Circulation 113:851-855

20. Ghosh P, Bhonsle N (1999) Inaccuracy of prediction of mitral valve prosthesis size. Asian Cardiovasc Thorac Ann 7:190-194

21. Yiu SF, Enriquez-Sarano M, Tribouilloy C, Seward JB, Tajik AJ (2000) Determinants of the degree of functional mitral regurgitation in patients with systolic left ventricular dysfunction: a quantitative clinical study. Circulation 102:1400-1406
22. Flachskampf FA, Chandra S, Gaddipatti A, Levine RA, Weyman AE, Ameling W, Hanrath P, Thomas JD (2000) Analysis of shape and motion of the mitral annulus in subjects with and without cardiomyopathy by echocardiographic 3-dimensional reconstruction. J Am Soc Echocardiogr 13:277-287

23. Timek TA, Miller DC (2001) Experimental and clinical assessment of mitral annular area and dynamics: what are we actually measuring? Ann Thorac Surg 72:966-974 